\title{
Seeking a new life in cyberspace
}

Previously published at www.cmaj.ca

\section{Spine}

Playwright Kevin Kerr; Director Bob Frazer Co-production University of Alberta and Realwheels

Mar. 10 to Mar. 20, 2010

In conjunction with the X Paralympic Games Fei and Milton Wong Experimental Theatre Vancouver, BC

$\mathrm{W}$ hat if you could leave a broken body and escape into limitless, anonymous cyberspace to craft a brand new frame - and life - that better matches your mind?

Spine, a new play recently staged in Edmonton, Alberta, and headed for Vancouver, British Columbia, probes this and related questions about the boundaries of how we define ourselves at the intersection of humanity and technology.

James (portrayed by James Sanders), who has been partially paralyzed and wheelchair-bound for 20 years, begins Spine at his wit's end. Left behind by his wife, his romantic advances on a caretaker rejected, he heads out to clear his head and ends up at a physical rehabilitation centre that is engrossed in experiments that involve controlling the mind and body. There he meets Carmela (Carmela Sison), who is much younger, but has been similarly disabled in a recent accident. She's a member of the Precursors, a bumbling, house-squatting artist collective. Enter into the fray Hokuto (Nikolai Witschl), a computergeek from Japan who introduces them to Second Life, an online world where one can craft an avatar and live large doing what you want, when and how you want - in an online world.

That's quite a tangle of plot threads to sort out and, in truth, it takes a while. But Kerr does eventually weave the strands into a cohesive and thought-provoking tapestry as he examines the ups and

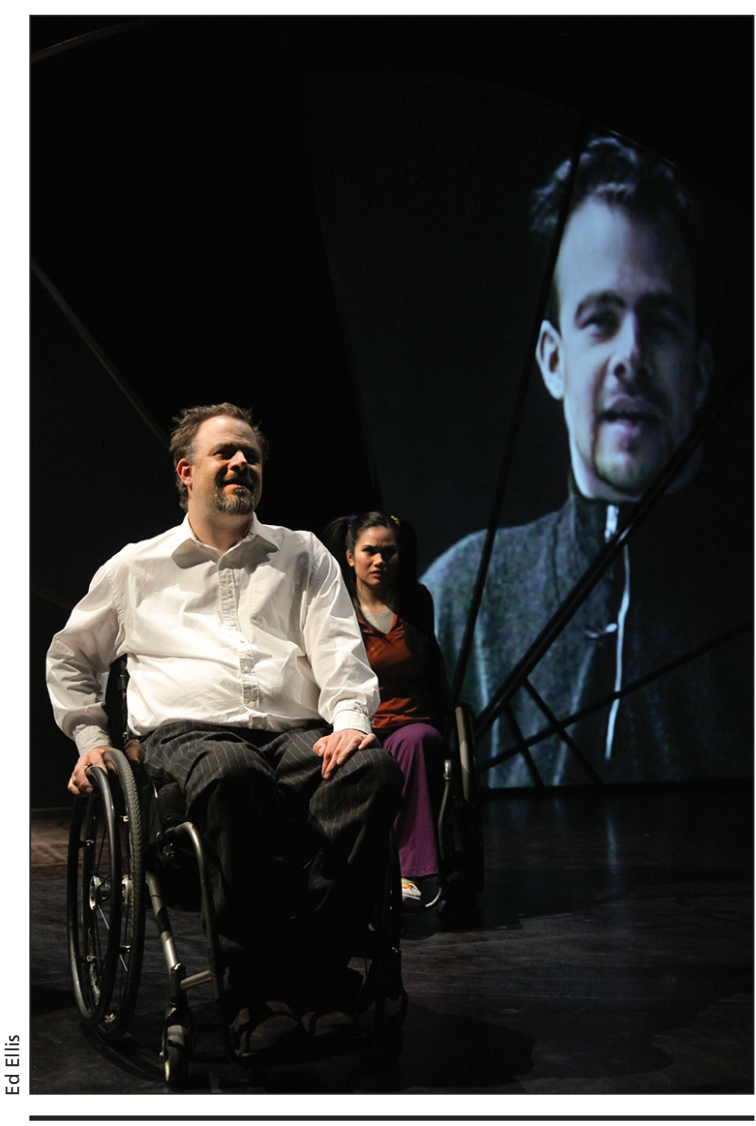

In Spine, two characters deal with disability in different ways. James pursues escape online, while Carmela opts for experimental neurological procedures to give her a new perceived reality.

downs of the online universe, where alternate lives without physical limitations are "lived."

For the person who is wheelchairbound, Second Life proves a wonderful escape - at first. James's selected avatar (excellently portrayed by Karyn Mott) is his antithesis: he is old and male, she is young and female. James embraces his online freedom with glee, happily blasting away at zombies and getting married, in scenes that are frequently funny.

However, as James discovers, the more the online world is embraced, the more it has real-world implications:
Taking another form (in this case, an online avatar) isn't so much an escape as it is a temporary vacation, a chance for the mind to play around in a different form. But ultimately, one is still burdened by the real body controlling it. This is probably the most fully developed point Spine makes.

By comparison, other plot lines that engage with questions of self Carmela adjusting to her disability, for example seem far less developed and are eventually incorporated into or overtaken by this main thread. There is no shortage of interesting ideas in Spine, but only a few of them really get the exploration they merit.

Technology itself structures Spine, which is unusual in a theatre production but surprisingly slick in its execution here. Most uses of multimedia - projections, opening and closing metal framework set, animated Second Life sequences - are quality enhancements, save one: Music and sound are controlled by the actors with attachments on their arms, but it's not always apparent who controls what, or how much.

Despite this, Spine succeeds in taking the audience into a curious, cyborg-y territory, blending tech and person in a manner that is well executed enough to warrant further examination. Stumbles are part of the research process, after all.

\section{Paul J. Blinov}

Critic

Edmonton, Alta. 